\begin{tabular}{|c|c|c|c|c|c|c|}
\hline \multirow{4}{*}{ Impact Factor: } & ISRA (India) & $=3.117$ & SIS (USA) & $=0.912$ & ICV (Poland) & $=6.630$ \\
\hline & ISI (Dubai, UAE & $=0.829$ & РИНЦ (Russia & $=0.156$ & PIF (India) & $=1.940$ \\
\hline & GIF (Australia) & $=0.564$ & ESJI (KZ) & $=8.716$ & IBI (India) & $=4.260$ \\
\hline & JIF & $=1.500$ & SJIF (Morocco & $=\mathbf{5 . 6 6 7}$ & OAJI (USA) & $=0.350$ \\
\hline
\end{tabular}

\section{SOI: $\underline{1.1 / \mathrm{TAS}}$ DOI: $\underline{10.15863 / \mathrm{TAS}}$ \\ International Scientific Journal Theoretical \& Applied Science}

p-ISSN: 2308-4944 (print) e-ISSN: 2409-0085 (online)

Year: 2019 Issue: $04 \quad$ Volume: 72

Published: 04.04.2019 http://T-Science.org
QR - Issue

QR - Article
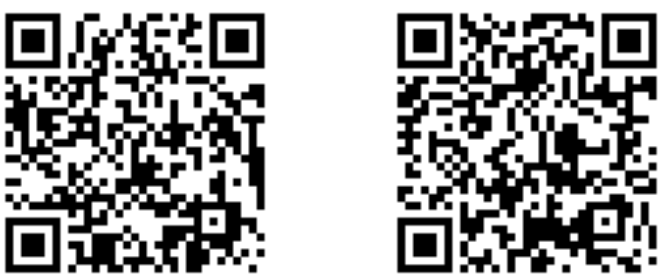

Gilbert Gilibrays Ocen

Lecturer,

Busitema University and Masinde Muliro University of

Science and Technology

gilbertocen@gmail.com

Makau Stephen Mutua

Lecturer,

Masinde Muliro University of Science and Technology

Gilbert Barasa Mugeni

Lecturer,

Communications Authority of Kenya

Simon Karume

Professor,

Laikipia University

Davis Matovu

Lecturer,

Busitema University and Masinde Muliro University of

Science and Technology

\title{
AN ALGORITHM AND PROCESS FLOW MODEL FOR THE EXTRACTION OF DIGITAL FORENSIC EVIDENCE IN ANDROID DEVICES
}

\begin{abstract}
The advancement in technology especially the use of mobile devices has revolutionized the way of life in the 21st century. This ranges from the way people socialize to the modes of business that take place today. Consequently, mobile devices have become very vital part of life and thus contain substantial amounts of private data. Accordingly, in event of crime and/or security investigations, these gadgets carry with them crucial evidence that when adduced before any court of law can aid in resolving a number of undetermined cases and appeals. However, mobile digital forensics research is still faced with a number of challenges. One popular challenge is seeking a standard process model to make the digital forensic evidence extraction process accurate and consistent. Earlier process models proposed, present basic steps that can be categorized as: collection, Examination, Analysis and Reporting. This has sparked significant research and proposition of numerous process models to try and explain these steps further sophisticating the problem and creating more complexity and inconsistencies, for this reason, sporadic increase in the use of mobile devices and huge volumes of data they carry that can be adduced as potential evidence in the event of dispute or court proceedings has raised the need to develop standardized extraction process models and procedures for mobile devices running android operating system, in this paper we propose an algorithm and process flow model for the extraction of digital evidence in android devices that can be adapted to the latest release of android operating system especially given the ongoing rapid changing nature of mobile device. Using this algorithm and process flow model, a procedural experiment was done on the extraction of digital evidence from an android device. The results of this experiment highlights key steps that must be followed and carefully documented during evidence extraction from mobile devices in order to ensure consistency and reduction of the complexities in early proposed models.
\end{abstract}




\begin{tabular}{|c|c|c|c|c|c|c|}
\hline \multirow{4}{*}{ Impact Factor: } & ISRA (India) & $=3.117$ & SIS (USA) & $=0.912$ & ICV (Poland) & $=6.630$ \\
\hline & ISI (Dubai, UAE & $=0.829$ & РИНЦ (Russia) & $=0.156$ & PIF (India) & $=1.940$ \\
\hline & GIF (Australia) & $=0.564$ & ESJI (KZ) & $=8.716$ & IBI (India) & $=4.260$ \\
\hline & JIF & $=1.500$ & SJIF (Morocco & $=5.667$ & OAJI (USA) & $=0.350$ \\
\hline
\end{tabular}

Key words: Process, Flow, Model, Digital, Forensic, Evidence, Mobile, Devices, Android.

Language: English

Citation: Ocen, G. G., Mutua, M. S., Mugeni, G. B., Karume, S., \& Matovu, D. (2019). An Algorithm and Process Flow Model for the extraction of Digital Forensic Evidence in Android Devices. ISJ Theoretical \& Applied Science, 04 (72), 1-10.

Soi: http://s-o-i.org/1.1/TAS-04-72-1 Doi: erostef https://dx.doi.org/10.15863/TAS.2019.04.72.1

\section{Introduction}

The proliferation of mobile devices and their use in day to activities raises the risk of such devices being used for criminal activities. Statistics indicate that $86.8 \%$ of mobile devices as at December 2018 were running on Android operating systems [1]. Android is an open source operating system designed for use on mobile devices and the basic composition of the operating system is the SDK (Software Development Kit) and applications which are a set of tools provided by Google that creates a development environment for developing Android compatible software[2]. The Android platform has unique characteristic features and different scenarios which a forensic analyst may come across, these unique characteristics raises issues of complexity and diversity of android based mobile devices which differ in terms of architecture, model and manufacturer design [3][4]. Therefore in the event of a need to extract forensic data from such devices, clear understanding of the architecture of the device plays a significant role in guiding the process model to be used and algorithm to follow [4]. A process model is a defined standard or method of getting things done by applying scientific methods [5]. While an algorithm is "a process or set of rules to be followed in calculations or other problem-solving operations, especially by a computer" [6]. Digital forensics is a term widely used to refer to the scientific method of identification, acquisition and analysis of digital evidence originating from digital devices, such as mobile phones, tablets, computers and wearable devices like smart watches[7]. Among the most urgent issues in digital forensics is the definition a process model that can make investigative and digital evidence process consistent and standardized. Several digital forensic process models have been defined with most of them focusing on necessary phases or groups of steps to be followed and sub-steps [5]. Therefore employing new methods and tools in the existing models for the extraction of digital evidence in android devices should improve efficiency in dealing with the problem of digital evidence extraction which is one of the challenges investigators face coupled with systematic documentation and reference procedures that should be provided [8], this has further raised challenges of performing data acquisition in a forensically sound manner from mobile devices, therefore to solve this problem this paper proposes an algorithm and process flow model for the extraction of digital evidence in mobile devices running on android.

\section{Contribution of this Work}

The contribution of this work can be summarized as follows:

- Discussed the current digital forensic process models,

- Reviewed literature on Digital forensic process models,

- Comparative analysis of existing models with the proposed model analyzing its benefits,

- Proposed an algorithm and process flow model for extraction digital evidence in Android devices

\section{Review of Related work}

Digital forensics is relatively a new research area but there has seen significant progressive work done ranging from the technology, tools and methodology, process models and frameworks used to extract, analyze, document and report. Those particularly related to this study are presented below:

\section{Evolution of Digital Forensic Process Models}

According to [5] a process model is the methodology used to conduct an investigation; a framework with a number of phases to guide an investigation. These process models were proposed and developed based on previous industrial experiences due to increase in cases such as cyberattacks, civil and criminal cases [5], the variation in these cases called for different investigation and extraction trends due to lack of standard workflow during investigation[9]. However [10] define standard methodology in digital forensics process model as comprising of sequences of actions with sub actions necessary for the investigation that must be ideal to be applied to as many cases as possible. Various process models have been proposed in the literature to date. Generally, each framework attempts to refine the standard methodology for a specific use case and each of these process models take a broadly similar approach. The earliest research concentrated on defining the process of digital forensic investigation [11] More recently, process model research centers around solving more specific issues like focusing on particular steps (evidence collection, preservation or examination, analysis) [5]. Numerous procedures have been proposed for the collection of digital forensic evidence in mobile devices beginning with committees such as the Digital Forensic Research 


\begin{tabular}{|c|c|c|c|c|c|c|}
\hline \multirow{4}{*}{ Impact Factor: } & ISRA (India) & $=3.117$ & SIS (USA) & $=0.912$ & ICV (Poland) & $=6.630$ \\
\hline & ISI (Dubai, UAE & $=0.829$ & РИНЦ (Russia) & $=0.156$ & PIF (India) & $=1.940$ \\
\hline & GIF (Australia) & $=0.564$ & ESJI (KZ) & $=8.716$ & IBI (India) & $=4.260$ \\
\hline & JIF & $=1.500$ & SJIF (Morocco) & )$=5.667$ & OAJI (USA) & $=0.350$ \\
\hline
\end{tabular}

Workshop Group (DFRWS) who proposed processes to be followed in extraction of digital evidence in computing and mobile devices since there were no standards forensic process in place to be followed by forensic investigators, several process models have been proposed and developed and these can be grouped in to three main categories; The first category were general models defining mainly process of digital forensic investigation detailing what should be done and steps to follow[12], the second category put emphasis on the investigative process itself on a case by case basis while the third category focused on defining problems associated with the methods and tools used in evidence extraction and how to solve them.

Building on the works of [13] who contend that digital forensic process model can be divided into several stages but majorly preservation, collection, examination and analysis, [14] examined a number of published models/framework for digital forensics whose basis is using the ideas from traditional (physical) forensic evidence collection strategy as practiced by law enforcement (e.g. FBI). In their examination, the authors argued that the proposed model can be termed as an enhancement of the DFRWS model since it is inspired from it, nine components emerged in their examination such as:

i. Identification - it recognizes an incident from indicators and determines its type. This component is important because it impacts other steps but it is not explicit within the field of forensic.

ii. Preparation - it involves the preparation of tools, techniques, search warrants and monitoring authorization and management support.

iii. Approach strategy - formulating procedures and approach to use in order to maximize the collection of untainted evidence while minimizing the impact to the victim.

iv. Preservation - it involves the isolation, securing and preserving the state of physical and digital evidence.

v. Collection - This is to record the physical scene and duplicate digital evidence using standardized and accepted procedures.

vi. Examination - An in-depth systematic search of evidence relating to the suspected crime. This focuses on identifying and locating potential evidence.

vii. Analysis - This determines importance and probative value to the case of the examined product

viii. Presentation - Summary and explanation of conclusion and Returning Evidence- Physical and digital property returned to proper owner.

The Efficient Generalized Forensics Framework for extraction and documentation of evidence from Android devices outlined by [8] put more emphasis on the consistency for a complete snapshot of Android devices through integrity verification using hashing algorithms. Generally speaking mobile devices forensics suffers from challenges in data acquisition and preservation as a result of many process models offered by different vendors[15]. The "Systematic Digital Forensic Investigation Model" proposed by [16], compared different process models and provided a mechanism upon which different frameworks can be implemented on the basis of technology, it is clear that this model is technology based and therefore does not address the 'challenges of inconsistencies raised by various platforms. Further[17] presented "Modeling the Forensics Process" in which the authors proposed a model with major stages that would be helpful in separating the flow stream, according to them, these stages comprises of creation, release, transfer, arrive, accept, and process. In this model the authors introduce totally new phases in mobile devices forensic evidence extraction. Finally "Models of Models: Digital Forensics and DomainSpecific Languages" proposed by[18] focused on the domain specific languages as very important part of digital forensic evidence investigation and extraction, their concern was on the domain/or platform used.

\section{Materials and Methods}

Comprehensive literature review formed the basis for the comparison between the proposed model and existing models, highlighted the key features implemented by android operating system that affect evidence extraction. An experimental setup for extracting digital evidence was done using Samsung s6 running android 8.0, Htc m8, android 7.0, Software used involved, Access Data Forensic Toolkit, Elcomsoft Forensics Toolkit, Software Development Kit, SQLite Browser Tools. Initial set up involved installing these software on a windows 10 machine. The process flow model was developed using Microsoft Viso studio.

\section{Results and Discussion}

The discussion of this research is presented in two parts, the first taking a comparatively look at the existing models discussed with the proposed while the second part is presenting the process flow model and the algorithm used in the proposed model and using this algorithm and process model to perform basic evidence extraction in android. The researchers began by identifying key features implemented in android operating system that influence in one way another evidence extraction from mobile devices on android operating system.

\section{Comparison with Existing Models}

Critical look at seven recently developed models for investigation and extraction of digital evidence 


\begin{tabular}{|c|c|c|c|c|c|c|}
\hline \multirow{4}{*}{ Impact Factor: } & ISRA (India) & $=3.117$ & SIS (USA) & $=0.912$ & ICV (Poland) & $=6.630$ \\
\hline & ISI (Dubai, UAE & $=0.829$ & РИНЦ (Russia & $=0.156$ & PIF (India) & $=1.940$ \\
\hline & GIF (Australia) & $=0.564$ & ESJI (KZ) & $=8.716$ & IBI (India) & $=4.260$ \\
\hline & JIF & $=1.500$ & SJIF (Morocco & $=5.667$ & OAJI (USA) & $=0.350$ \\
\hline
\end{tabular}

reveals that it may not be easily possible to have a oneto-one mapping between the activities in the proposed model and other previous models. Though the processes may be similar, the terms and definition of the phases used in the proposed model differs from those in the existing models reviewed.

Table.1 comparison of the proposed model with the existing models.

\begin{tabular}{|l|c|c|c|c|c|c|c|}
\hline $\begin{array}{l}\text { Process/Phases } \\
\text { in the Proposed } \\
\text { model }\end{array}$ & $\begin{array}{l}\text { HIST } \\
\text { Guidelines[10] }\end{array}$ & $\begin{array}{l}\text { Hodel } \\
\text { [19] }\end{array}$ & $\begin{array}{l}\text { DEFSOP } \\
\text { [20][12] }\end{array}$ & SDFIM[21] & MFP[17] & SFIM[22] & DFRWS[23] \\
\hline $\begin{array}{l}\text { Device status } \\
\text { check }\end{array}$ & $\mathbf{x}$ & $\mathbf{x}$ & $\mathbf{x}$ & $\mathbf{x}$ & $\mathbf{x}$ & $\mathbf{x}$ & $\mathbf{x}$ \\
\hline Preparation & $\mathbf{x}$ & $\checkmark$ & $\checkmark$ & $\checkmark$ & $\mathbf{x}$ & $\checkmark$ & $\checkmark$ \\
\hline $\begin{array}{l}\text { Identify } \\
\text { evidence }\end{array}$ & $\checkmark$ & $\checkmark$ & $\mathbf{x}$ & $\checkmark$ & $\checkmark$ & $\checkmark$ & $\checkmark$ \\
\hline Recover data & $\mathbf{x}$ & $\mathbf{x}$ & $\mathbf{x}$ & $\mathbf{x}$ & $\mathbf{x}$ & $\mathbf{x}$ & $\mathbf{x}$ \\
\hline $\begin{array}{l}\text { Forensic } \\
\text { analysis }\end{array}$ & $\checkmark$ & $\mathbf{x}$ & $\checkmark$ & $\checkmark$ & $\checkmark$ & $\checkmark$ & $\checkmark$ \\
\hline Verification & $\mathbf{x}$ & $\mathbf{x}$ & $\mathbf{x}$ & $\mathbf{x}$ & $\mathbf{x}$ & $\mathbf{x}$ & $\mathbf{x}$ \\
\hline Documentation & $\checkmark$ & $\checkmark$ & $\mathbf{x}$ & $\mathbf{x}$ & $\mathbf{x}$ & $\checkmark$ & $\mathbf{x}$ \\
\hline
\end{tabular}

On the basis of steps or phases involved in the process models reviewed, it can be concluded the proposed model is most suitable because it summarizes most of the phases and steps proposed in earlier models and reveals the complexities in the models reviewed for example a look at:

NIST Guidelines shows that it has very limited steps; therefore they are not appropriate enough for performing digital evidence extraction thoroughly.

The Harmonized Digital Forensic investigation model presents preparation, identification and documentation stages which this proposed model also address however a critical consideration of device status check is ignored in this model, forensic analysis , recovery of data and verification which are key concerns in digital evidence extraction have also not been clearly addressed.
Though the Digital Evidence Forensic Standard Operating Procedure, The Systematic Digital Forensic Investigation model and Modeling the Forensic Process all present several phases or steps to be followed, it can be noted that there are several repetitions in these stages and all of them concentrate more on the investigation itself other than extraction which the proposed model addresses right from device seizure to evidence extraction.

The Smartphone Forensic investigation model is close to the proposed model except that it concentrated more on the investigation other than evidence extraction and critically lacks the device status check and data recovery phases as pointed out in the proposed model as one of the key critical issues in digital evidence extraction in android devices. 


\begin{tabular}{|c|c|c|c|c|c|c|}
\hline \multirow{4}{*}{ Impact Factor: } & ISRA (India) & $=3.117$ & SIS (USA) & $=0.912$ & ICV (Poland) & $=6.630$ \\
\hline & ISI (Dubai, UAE & $=0.829$ & РИНЦ (Russia & $=\mathbf{0 . 1 5 6}$ & PIF (India) & $=1.940$ \\
\hline & GIF (Australia) & $=0.564$ & ESJI (KZ) & $=8.716$ & IBI (India) & $=4.260$ \\
\hline & JIF & $=1.500$ & SJIF (Morocco & $=5.667$ & OAJI (USA) & $=0.350$ \\
\hline
\end{tabular}

\section{Proposed algorithm}

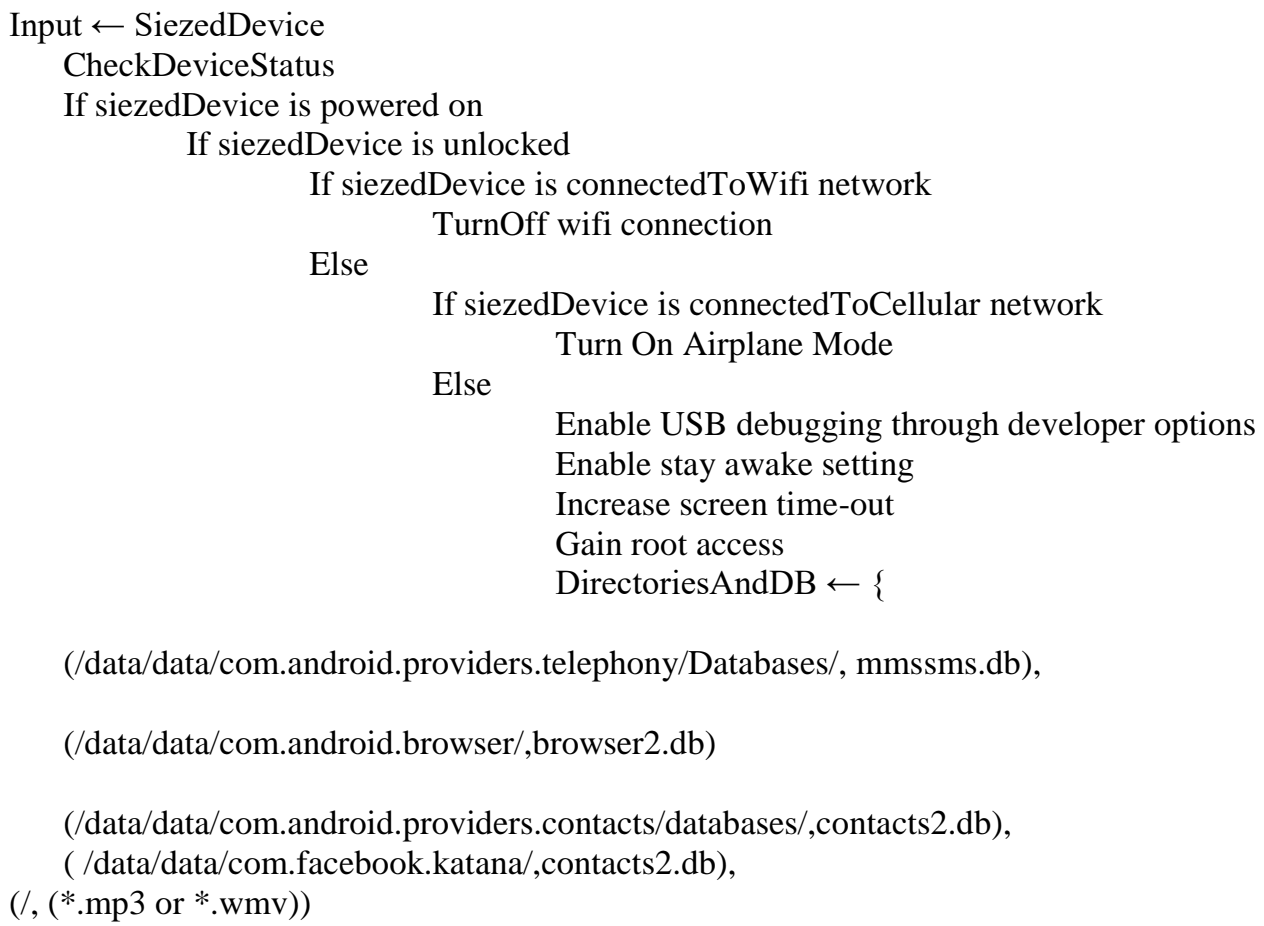

(/data/data/com.android.providers.telephony/Databases/, mmssms.db),

(/data/data/com.android.browser/,browser2.db)

(/data/data/com.android.providers.contacts/databases/,contacts2.db),

( /data/data/com.facebook.katana/,contacts2.db),

$(/,(* . m p 3$ or *.wmv))

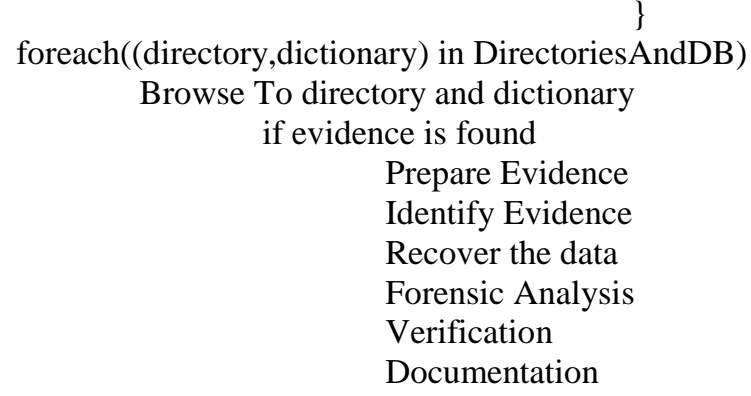

Else

$$
\begin{aligned}
& \begin{array}{l}
\text { If siezedDevice. Android Version }>=6 \\
\text { Obtain Passcode }
\end{array} \\
& \text { Else } \quad \text { ByPass Lock }
\end{aligned}
$$

Else

Power on siezedDevice

Table 2: Android Features and their level of implementation affect evidence extraction[24][25] [26]

\begin{tabular}{|l|l|l|}
\hline No & Feature & Implementation \\
\hline 1. & On device encryption & implemented \\
\hline 2. & External storage encryption & implemented \\
\hline 3. & Privacy of synchronization & $\begin{array}{l}\text { Partially implemented by third party } \\
\text { apps }\end{array}$ \\
\hline 4. & Sync to cloud communication encryption & implemented \\
\hline 5. & Wireless anti- tracking & $\begin{array}{l}\text { Not Implemented, need to use third } \\
\text { party apps }\end{array}$ \\
\hline 6. & Remote device location tracking & implemented \\
\hline
\end{tabular}




\begin{tabular}{|c|c|c|c|c|c|c|}
\hline \multirow{4}{*}{ Impact Factor: } & ISRA (India) & $=3.117$ & SIS (USA) & $=0.912$ & ICV (Poland) & $=6.630$ \\
\hline & ISI (Dubai, UAE & $=0.829$ & РИНЦ (Russia & $=0.156$ & PIF (India) & $=1.940$ \\
\hline & GIF (Australia) & $=0.564$ & ESJI (KZ) & $=8.716$ & IBI (India) & $=4.260$ \\
\hline & JIF & $=1.500$ & SJIF (Morocco & $=5.667$ & OAJI (USA) & $=0.350$ \\
\hline
\end{tabular}

\begin{tabular}{|l|l|l|}
\hline 7. & Remote device locking and or data wipe & implemented \\
\hline 8. & $\begin{array}{l}\text { Zero knowledge encryption (access to customer cloud data by } \\
\text { the Mobile Platform Owner) }\end{array}$ & No knowledge \\
\hline 9. & $\begin{array}{l}\text { Secure Enclave Processors for firmware protection and } \\
\text { supporting encryption }\end{array}$ & implemented \\
\hline 10. & Limiting Device Access & implemented \\
\hline
\end{tabular}

Based on the information presented on table 2, it is evident that any process model for the extraction of digital forensic evidence in android should consider architectural design of the platform so as to ensure

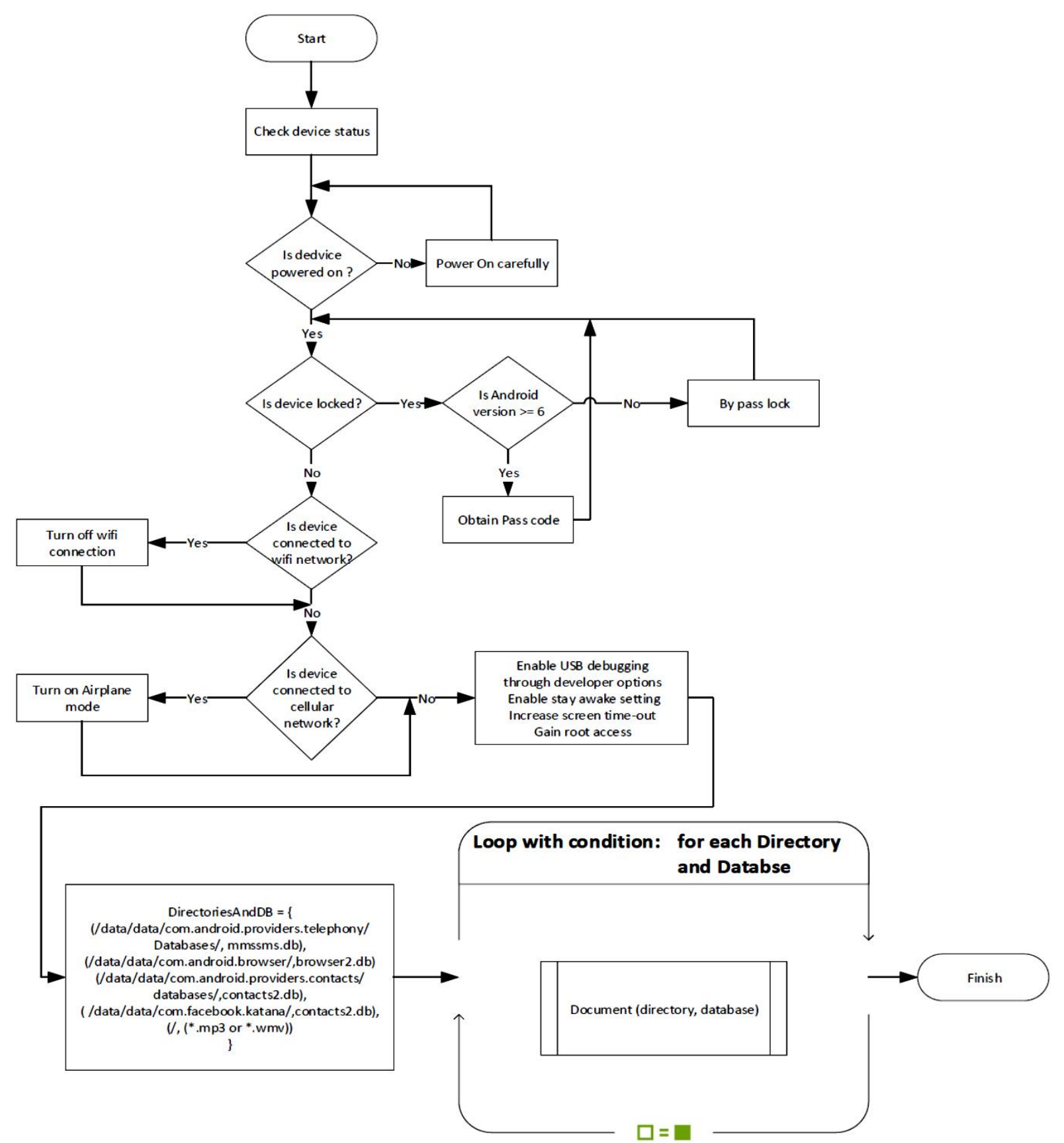

consistency in evidence extraction and security issues that affect evidence extraction. The information on table2 informed the model design presented in Figl.

Figure 1: Process flow model 


\begin{tabular}{|c|c|c|c|c|c|c|}
\hline \multirow{4}{*}{ Impact Factor: } & ISRA (India) & $=3.117$ & SIS (USA) & $=0.912$ & ICV (Poland) & $=6.630$ \\
\hline & ISI (Dubai, UAE & $=0.829$ & РИНЦ (Russia & $=\mathbf{0 . 1 5 6}$ & PIF (India) & $=1.940$ \\
\hline & GIF (Australia) & $=0.564$ & ESJI (KZ) & $=8.716$ & IBI (India) & $=4.260$ \\
\hline & JIF & $=1.500$ & SJIF (Morocco & $=5.667$ & OAJI (USA) & $=0.350$ \\
\hline
\end{tabular}

1. At the start, the device status is checked, that is; power status, Wi-Fi connection status and cellular network status. This is done to ensure that the device is powered on and not having any network connection. Thereafter, USB debugging is enabled through developer options, screen timeout is increased and root access is gained.
2. Then browse to different locations, and get SQLite databases which can be opened to get evidence, which is later documented using Document_(directory, dictionary). It follows similar steps while documenting every stage to ensure consistency.

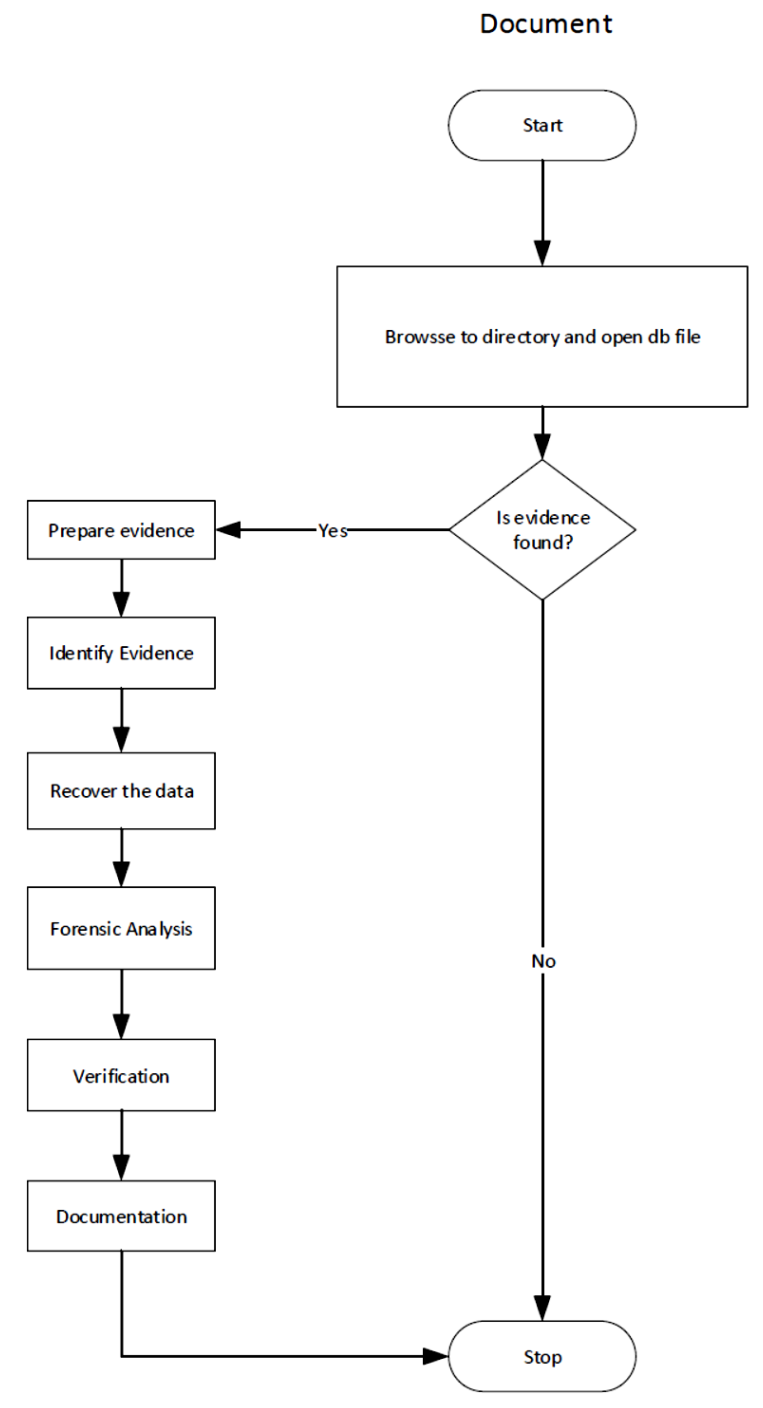

Figure 2: Extension of the process flow model with documentation of every phase

In this proposed model, once the device status is checked and necessary access procedures followed as per Figure 1, every directory is browsed to open $\mathbf{d b}$ file to check if evidence is found and at every step documentation is taken. In the context of this model, the meaning of these phases are further elaborated below:

\section{Device status check}

If the device's display is in a viewable state, the screen's contents should be photographed and, if necessary, recorded manually, capturing the time, service status, battery level, and other displayed icons. The main consideration is selecting a tool that reports the status of any PINs and recovers the data of interest. 


\begin{tabular}{|c|c|c|c|c|c|c|}
\hline \multirow{4}{*}{ Impact Factor: } & ISRA (India) & $=3.117$ & SIS (USA) & $=0.912$ & ICV (Poland) & $=6.630$ \\
\hline & ISI (Dubai, UAE & $=0.829$ & РИНЦ (Russia) & $=0.156$ & PIF (India) & $=1.940$ \\
\hline & GIF (Australia) & $=0.564$ & ESJI (KZ) & $=8.716$ & IBI (India) & $=4.260$ \\
\hline & JIF & $=1.500$ & SJIF (Morocco & $=5.667$ & OAJI (USA) & $=0.350$ \\
\hline
\end{tabular}

If the mobile device is powered on, the information appearing on the display may aid in mobile device identification

\section{Prepare evidence}

This entails the preparation of tools, techniques, search warrants, and monitoring authorizations and management support. The preparation phase involves specific research the regarding the particular phone to be examined, the appropriate tools to be used during the examination and preparation of the examination machine to ensure that all of the necessary equipment, cables, software and drivers are in place for the examination. Once the make and model of the phone have been identified, the examiner can then research the specific phone to determine what available tools are capable of extracting the desired data from the phone.

\section{- Identify evidence}

In this model Identification of evidence is gathering information that the investigator require as potential evidence. Questions regarding where the information is located, what information is required and how it should be gathered are key to the investigator at this phase.

\section{- Recover data}

This phase deals with discovery of deleted, hidden, transfigured data or non-displayable data and is conducted on duplicate data got from imaging the memory.

\section{- Forensic analysis}

Forensic analysis phase helps in "drawing conclusions based on evidence found". It involves determination of the significance, reconstructing fragments of data and drawing conclusions based on evidence found.

\section{- Verification}

Verification in this model is the process of ascertaining and evaluating component to determine if a given result or product conform to pre-set conditions at the start of each life cycle and consequently in all activities and set criteria.

\section{- Documentation}

Documentation deals with the means and mechanisms of for describing the overall extraction process either by using graphics, texts or both. Documentation should be comprehensive enough to support decision making at all stages of legal and court proceedings.

\section{EXPERIMENTATION}

Before the experiment was conducted, a check was done to determine whether the device is still active (unlocked) and the settings of the device were changed to enable greater access to the device. For an active device the following tasks were done;

1. Enabling USB debugging to give greater access to the device through the adb connection since most methods for physical acquisition in android devices require USB debugging to be enabled

2. Enabling the Stay awake setting: If the Stay awake option is selected and the device is connected for charging, then the device never locks. Again, if the device locks, the acquisition can be halted.

3. Increasing screen timeout: This is the time for which the device will be effectively active once it is unlocked. The location to access this setting varies depending upon the model of the device. On a Samsung phone, you can access the same by navigating to Settings | Display | Screen Timeout.

4. Gaining root access since this helps in understanding the internal workings of the device in detail and comprehend many issues during evidence extraction. The process of rooting varies depending on the underlying device manufacturer. However, rooting any device usually involves exploiting a security bug in the device's firmware and software then copying the su (superuser) binary to a location in the current process's path $(/$ system/xbin/su) and granting it executable permissions with the chmod command.

During physical acquisition the JTAG interface was used since it allows for complete extraction of memory and is supported by many mobile forensic tool vendors. While during logical extraction the Android Debugging Bridge (ADB) was used to pull data extraction since this tool works for Android 4.2.2 and has secure USB debugging and is supported by the command line SDK tool. Cosidering that data to be extracted on an android phone can be stored in shared preference under shared_pref/data_directory, internal storage, external storage under /sdcard directory, but importantly the SQLite database where data is stored the /data/data/PackageName/ database and can be extracted by executing SQLite commands on the respective files 


\begin{tabular}{|c|c|c|c|c|c|c|}
\hline \multirow{4}{*}{ Impact Factor: } & ISRA (India) & $=3.117$ & SIS (USA) & $=0.912$ & ICV (Poland) & $=6.630$ \\
\hline & ISI (Dubai, UAE & $=0.829$ & РИНЦ (Russia & $=\mathbf{0 . 1 5 6}$ & PIF (India) & $=1.940$ \\
\hline & GIF (Australia) & $=0.564$ & ESJI (KZ) & $=8.716$ & IBI (India) & $=4.260$ \\
\hline & JIF & $=1.500$ & SJIF (Morocco & $=5.667$ & OAJI (USA) & $=0.350$ \\
\hline
\end{tabular}

Using adb, the data present in this partition was extracted for further analysis using the adb pull folder of the Dropbox app was executed as follows: command. The adb pull command on the databases

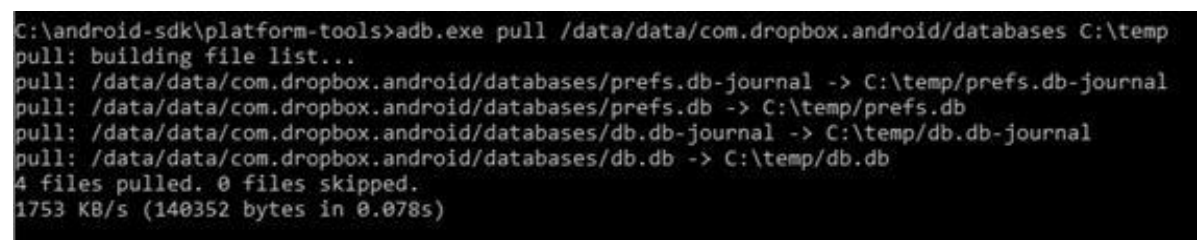
folder

Figure 3: ADB Dropbox app for database

Similarly, on a rooted phone, the entire /data folder was pulled in this manner, as shown in Fig. 3 ..., also the complete /data directory on the Android device was copied to the local directory on the machine for analysis. The entire data directory was extracted in 97 seconds. This extraction time varies depending on the amount of data residing in /dat/ adb.exe pull /data c: :temp

Whereas On a non-rooted device, a pull command on the /data directory does not extract the files, as shown in Fig 4, since the shell user does not have permission to access those files

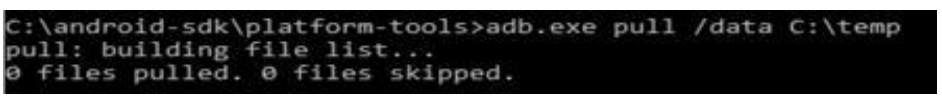

\section{Figure 4. Pulling data on rooted device}

The data was copied from a rooted phone through the preceding process so as to maintain its directory structure, thus allowing for browsing through the necessary files to gain access to the information. This was done through analysis and examination of critical information while taking keen note on the dates and time comparison and with careful documentation. Using SQLite Browser to view this information, database files such as .qlite, .sqlite3, .sqlitedb, .db and . $\mathrm{db} 3$ were browsed to view the contents and shown in Fig.5

\begin{tabular}{|c|c|c|c|c|c|}
\hline \multicolumn{4}{|c|}{ @ SQLite Database Browser - C:/temp/databases/profiledb } & \multicolumn{2}{|c|}{ 回回 $x$} \\
\hline \multicolumn{6}{|c|}{ File Edit View Help } \\
\hline \multicolumn{3}{|c|}{ 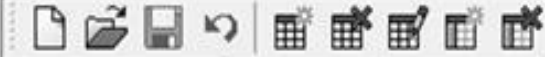 } & \multicolumn{2}{|c|}{ (100 } & \\
\hline Database Structure & Browse Data & Execute $S Q$ & & & \\
\hline Name & & Object & Type & Schems & 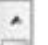 \\
\hline +-android_metadat & & table & & CREATE TABLE android_metadata (local... & \\
\hline +.sync_state & & table & & CREATE TABLE_sync_state (Jid INTEGE... & 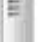 \\
\hline t) packages & & table & & CREATE TABLE packages (IId DNTEGER ... & \\
\hline 4-mimetypes & & table & & CREATE TABLE mimetypes (id INTEGER... & \\
\hline f-data & & table & & CREATE TABLE data Cid INTEGER PRIM... & \\
\hline
\end{tabular}

Figure: 5 SQLite Database Browser

\section{Conclusion and Future work}

A process flow model and an algorithm has been developed for the extraction of digital evidence in android devices with emphasis on technical and core concept of evidence extraction process. The proposed model is starts with checking of the device status and follows with all necessary security checks and android operating system version checks. An experiment was conducted the test this model and the results showed greater efficiency. It is shown through examples that the method can uniformly specify the forensic process 


\begin{tabular}{|c|c|c|c|c|c|c|}
\hline \multirow{4}{*}{ Impact Factor: } & ISRA (India) & $=3.117$ & SIS (USA) & $=0.912$ & ICV (Poland) & $=6.630$ \\
\hline & ISI (Dubai, UAE & $=0.829$ & РИНЦ (Russia & $=\mathbf{0 . 1 5 6}$ & PIF (India) & $=1.940$ \\
\hline & GIF (Australia) & $=0.564$ & ESJI (KZ) & $=8.716$ & IBI (India) & $=4.260$ \\
\hline & JIF & $=1.500$ & SJIF (Morocco & $=5.667$ & OAJI (USA) & $=0.350$ \\
\hline
\end{tabular}

in various phases and provides a more exact description and process flow of how evidence can be extracted by browsing each directory and documenting each stage in the evidence extraction.
Further research aims at experimenting this model with latest android operating system version to ensure consistency in results obtained.

\section{References:}

1. (2019). Statista 2019, Mobile OS market share 2018 Statista. Retrieved April 01, 2019, from https://www.statista.com/statistics/266136/glob al-market-share-held-by-smartphone-operatingsystems/

2. Renner, T. (n.d.). Mobile OS - Features, Concepts and Challenges for Enterprise Environments.

3. Al-Hadadi, M., \& AlShidhani, A. (2013). Smartphone Forensics Analysis: A Case Study. Int. J. Comput. Electr. Eng., vol. 5, no. 6, 576580.

4. Rao, V., \& A. S. (2016). Survey on Android Forensic Tools and Methodologies. Int. J. Comput. Appl., vol. 154, no. 8, 17-21.

5. Du, X., \& Scanlon, M. (2016). Evaluation of Digital Forensic Process Models with Respect to Digital Forensics as a Service.

6. (2019). oxford dictionary online. algorithm | Definition of algorithm in English by Oxford Dictionaries. Retrieved April 01, 2019, from: https://en.oxforddictionaries.com/definition/alg orithm

7. Daware, S., Dahake, S., \& Thakare, V. M. (2012). Mobile forensics: Overview of digital forensic, computer forensics vs. mobile forensics and tools. Int. J. Comput. Appl., vol. 2012, 7-8.

8. Ahmed, R., Dharaskar, R., \& Thakare, V. (2013). Digital evidence extraction and documentation from mobile devices. Int. J. Adv. Res. Comput. Commun. Eng., vol. 2, no. 1, 10191024.

9. Lawton, D., Stacey, R., \& Dodd, G. (2014). eDiscovery in digital forensic investigations.

10. Ayers, R., Brothers, S., \& Jansen, W. (2014). NIST Special Publication 800-101 Revision 1: Guidelines on Mobile Device Forensics. NIST Spec. Publ., vol. 1, no. 1, 85.

11. Kohn, M. D., Eloff, M. M., \& Eloff, J. H. P. (2010). Integrated digital forensic process model. (pp.1-13).

12. Khadijah, S., Mohd, T., Adil, Z., \& Talib, B. (2013). Standard operating procedure of digital evidence collection. Digital Forensics Department, CyberSecurity Malaysia.
13. K. R., \& Amandeep, K. (2012). Digital Forensics. Int. J. Comput. Appl., vol. 50, no. 5, 5-9.

14. Jafari, F., \& Satti, R. S. (2015). Comparative Analysis of Digital Forensic Models. J. $A d v$. Comput. Networks, vol. 3, no. 1, 82-86.

15. Anobah, M., Saleem, S., \& Popov, O. (2014). Testing Framework for Mobile Device Forensics Tools DEVICE FORENSICS TOOLS. J. Digit. Forensics, Secur. Law Artic., vol. 9, no. 2.

16. Agarwal, M., \& Gupta, M. (2011). Systematic digital forensic investigation model. Int. J. Comput. Sci. Secur., vol. 5, no. 1, 118-131.

17. Al-Fedaghi, S., \& Al-Babtain, B. (2012). Modeling the forensics process. Int. J. Secur. its Appl., vol. 6, no. 4, 97-108.

18. Ray, D. A., \& Bradford, P. G. (2007). Models of Models: Digital Forensics and Domain-Specific Languages A Selection of Previous Work on Models of Digital Investigation. no. May, p. 108.

19. Valjarevic, A., \& Venter, H. S. (2012). Harmonised digital forensic investigation process model. 2012 Inf. Secur. South Africa Proc. ISSA 2012 Conf.

20. Perumal, S., \& Md Norwawi, N. (2011). New improvement in digital forensic standard operating procedure (SOP).

21. Gupta, Y. K. (2016). Systematic Digital Forensic Investigation Model. no. January 2011.

22. Goel, A., Tyagi, A., \& Agarwal, A. (2012). Smartphone Forensic Investigation Process Model. J. Comput. Sci. ..., no. 6, 322-341.

23. Pollitt, M. (n.d.). Digital forensic research conference. A Framework for Digital Forensic Science.

24. Shibly, A. (2016). Android Operating System: Architecture, Security Challenges and Solutions. no. March.

25. Pandiyan, D., \& Paranjape, S. (n.d.). Android architecture and binder.

26. Bala, K. (2015). A Study on Smartphone based Operating System. vol. 121, no. 1, 17-22. 